\title{
Micro ultrasonic motor for miniature robot arm
}

\author{
Shigeki Toyama ${ }^{1}$, Uichi Nishizawa ${ }^{2}$ \\ Tokyo University of Agriculture and Technology, Tokyo, Japan \\ ${ }^{1}$ Corresponding author \\ E-mail: ${ }^{1}$ toyama@cc.tuat.ac.jp, ${ }^{2}$ n-uichi@cc.tuat.ac.jp \\ Received 23 August 2017; accepted 24 August 2017 \\ DOI https://doi.org/10.21595/vp.2017.18999
}

Check for updates

\begin{abstract}
The purpose of this study is development of micro ultrasonic motor for miniature robot arm. It will be assembled to a miniature robot applied to a mesh robot to represent the shape and stiffness of the surface of objects. In the first stage, the authors have developed a micro motor by ultrasonic technology. It has two components: a stator (a cube of $3 \mathrm{~mm}$ size) and a rotor (diameter of $1 \mathrm{~mm}$ ). The authors have designed a new stator and a rotor to increase output torque. The first trial motor shows successfully the potential of the final goal of $5 \mu \mathrm{Nm}$ and $3 \mathrm{rpm}$ with a reduction gear system.
\end{abstract}

Keywords: ultrasonic motor, micro motor, mesh robot.

\section{Introduction}

There are special robots and manipulators working in the hazardous environment such as deep sea, outer space or atomic plants. In these applications, master-slave type of robot is widely used; the operators control the robots and obtain the information of handling objects such as contact force, temperature and visionary information from the robot's sensors. This is tele existence technology. The tele existence needs the function of the tactile presentation of the objects such as shape and stiffness and so on. It is important technology because the robots are handling much far away from the operators, but they have to feel the object by themselves to precede a sophisticated task. For these applications, the authors have proposed a new tactile presentation device as shown in Fig. 1. This is a mesh type of robot. It moves each plate to desired direction and position respectively to show the shape of the target objects. It can also show the stiffness and smoothness of the surface by controlling compliance of the mesh robot.

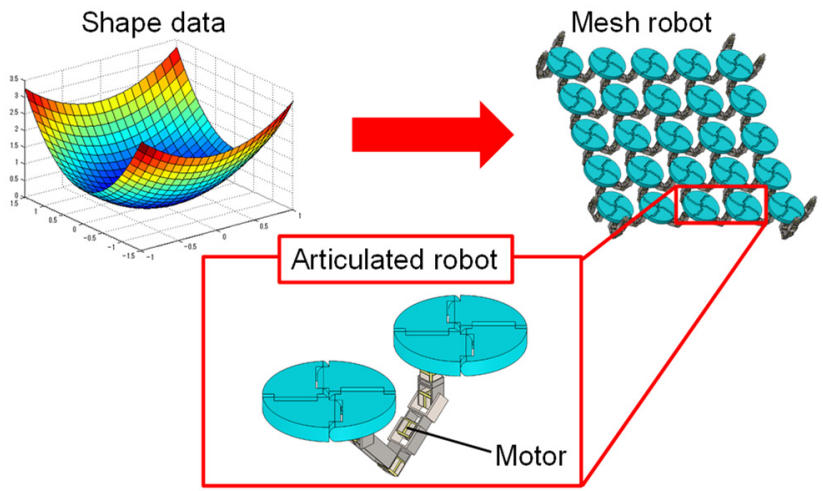

Fig. 1. Schematic diagram of mesh robot

In this study, the authors have developed a micro motor adapted for the robots of mesh robot as the first stage. The specification of the motor is as follows:

1) It should be as large as a $3 \mathrm{~mm}$-sized cubic or smaller.

2) It should have the maximum output torque of $5 \mu \mathrm{Nm}$ or more.

3 ) It should have the maximum rotational speed of $3 \mathrm{rpm}$ or more.

Now that it is difficult that only one motor meets the specification actually, the authors have prepared a small reduction gear system. The authors have also applied ultrasonic technology to 
develop the motor in order to reduce the size of it [1-6]. This is vibromotor and driven by ultrasonic vibration.

\section{Newly designed stator and rotor}

A new motor consists of a stator and a rotor. The rotor is made of phosphor bronze with a through hole in the center (Fig. 2). The hole of the stator is tapered to obtain wedge effect. It contributes contact force control between the stator and the rotor to increase and make adjustment easily. The contact force can be controlled by a spring in it. Adding that, the surface of hole has teeth; it also contributes to driving the rotor firmly at the edge of teeth and the resonant frequency decrease for driving.

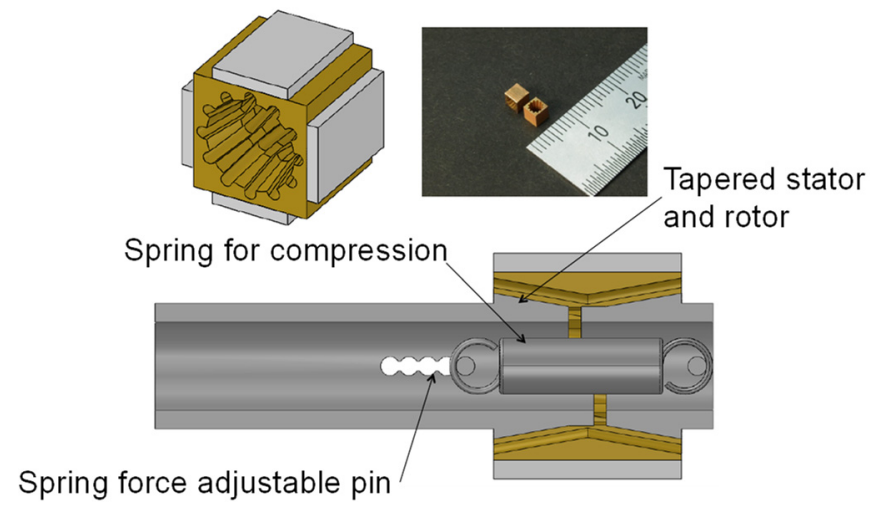

Fig. 2. Overview of a new motor

In the design stage, the authors have made FEM analysis of the vibration of the stator with and without teeth. The authors have assumed to adopt three-wave vibration mode. Suppose that one wave correspond four teeth, the hole should have twelve teeth. Ideally it should have sixteen teeth or more to transmit the force firmly, but the production process in a small hole is limited.

Fig. 3 shows vibration modes by FEM analysis. Three elastic waves are traveling along the surface. Both vibration modes are expected to drive the rotor effectively. However, the resonant frequency with teeth model is much lower than that of the model without teeth. Generally speaking, lower resonant frequency has advantage for controlling it due to wider frequency range.

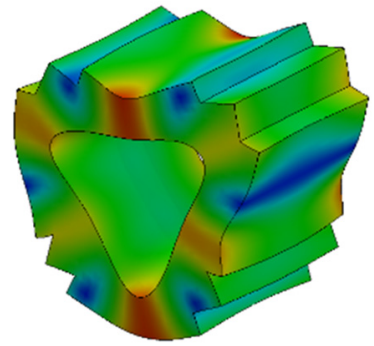

a) Without teeth

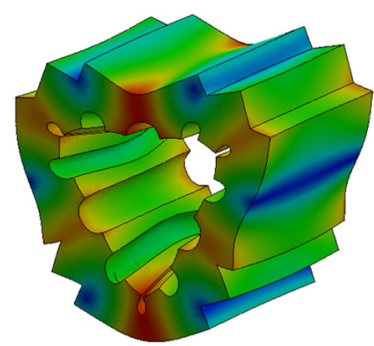

b) With teeth

Fig. 3. Vibration mode of rotation

Next, the authors have made each our stators with and without teeth and measured resonant frequencies. The results are also shown in Fig. 4 and Table 1. It shows that each stator's resonant frequency meets good coincidence with that of analysis results and the errors among each stato's frequencies are small because the production process of the stators is controlled carefully.

Finally, piezoelectric ceramics are laminated on the side faces of each stator. Alternative voltage is applied to each ceramic with phase difference as shown in Fig. 5. 
Table 1. Resonance frequency

\begin{tabular}{|c|c|c|}
\hline \multirow{2}{*}{ Eigenvalue analysis } & Without teeth & With teeth \\
\cline { 2 - 3 } & $353.5 \mathrm{kHz}$ & $245.5 \mathrm{kHz}$ \\
\hline ch 1 & $345.8 \mathrm{kHz}$ & $248.3 \mathrm{kHz}$ \\
\hline ch 2 & $345.6 \mathrm{kHz}$ & $248.3 \mathrm{kHz}$ \\
\hline ch 3 & $345.8 \mathrm{kHz}$ & $248.0 \mathrm{kHz}$ \\
\hline ch 4 & $345.6 \mathrm{kHz}$ & $248.2 \mathrm{kHz}$ \\
\hline
\end{tabular}

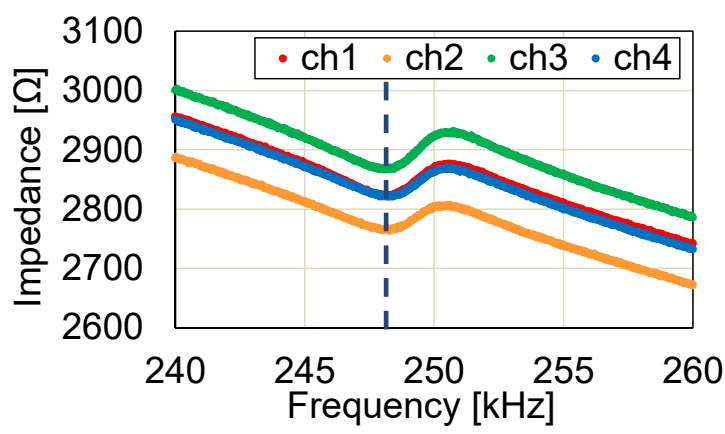

Fig. 4. Measurement of impedance

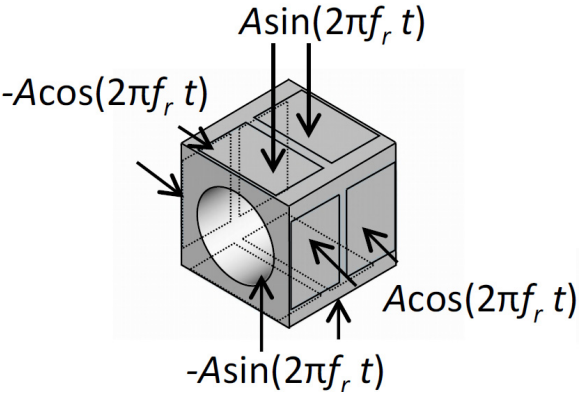

Fig. 5. Applied voltage

\section{Characteristics of the motor}

The authors have made experiments of characteristics of the motor. The experimental apparatus is shown in Fig. 6-7. The motor is supported with acrylic plate so as to avoid suppressing driving vibration of the motor. A small magnetic device measures the rotational speed and position.

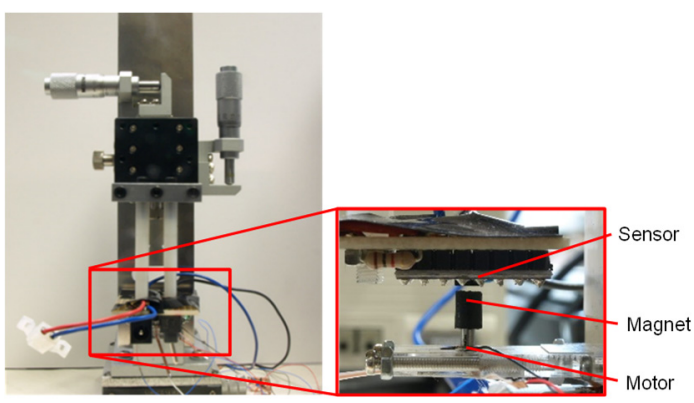

Fig. 6. Experimental apparatus

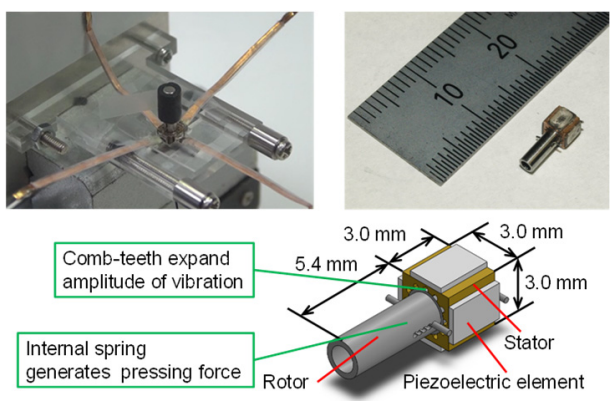

Fig. 7. The new motor

Firstly, the authors have evaluated the resonant frequency characteristics. The results are shown in Fig. 8 and Table 2. The stator with teeth has wider frequency control range. It is the advantage of the control because the controllable range of the ultrasonic motor with higher resonant frequency is generally narrow and it causes poor controllability.

Secondly, the authors have evaluated rotational speed by changing phase difference of every ten degree. The results are shown in Fig. 9. The stator without teeth shows dead zone at phase difference zero, however the stator with teeth shows the smooth sinusoidal curve without dead zone (the error speed at phase zero is caused by offset in a driving circuit or miss alignment of the ceramics and it is adjustable easily).

Thirdly, the authors have estimated the rotational speed changing applied voltage. The results are shown in Fig. 10. The stator with teeth shows higher speed at the same applied voltage. Based on the above discussion and experiments, the authors have concluded to adopt the stator with teeth.

Finally, the authors have made experiment of output torque by using simple pulley and weight 
method. The results show that maximum output torque is $12 \mu \mathrm{Nm}$, and maximum rotational speed is $2000 \mathrm{rpm}$. Now that the authors have prepared the reduction gear system with sixty-eight gear ratio, the output torque of the gear is about $0.8 \mu \mathrm{Nm}$ and rotational speed is about $30 \mathrm{rpm}$. The specification of it is $5 \mu \mathrm{Nm}$ and $3 \mathrm{rpm}$. Therefore, the output toque of the motor should be more than $70 \mu \mathrm{Nm}$ but rotational speed can be around $200 \mathrm{rpm}$.

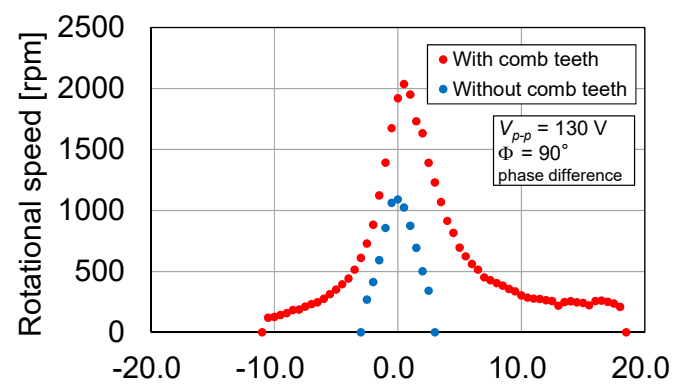

Difference from reference frequency $[\mathrm{kHz}]$

Fig. 8. Characteristics of resonant frequency

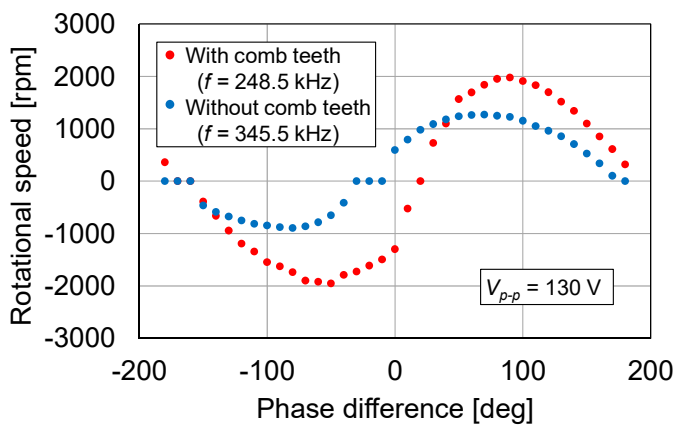

Fig. 9. Rotational speed versus phase difference

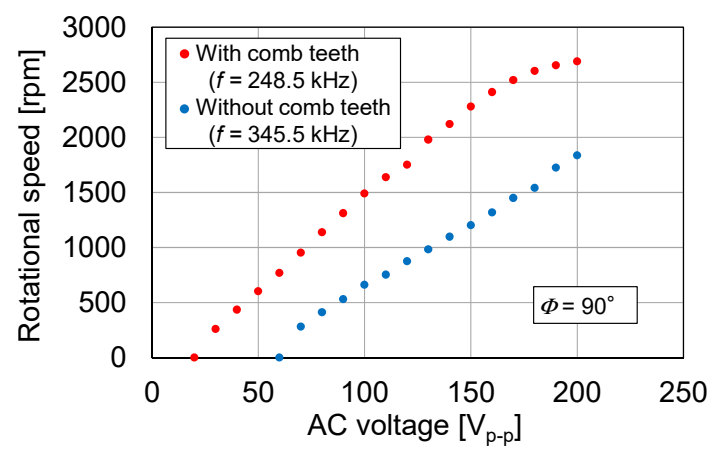

Fig. 10. Rotational speed versus applied voltage

Table 2. Characteristics of resonant frequency

\begin{tabular}{|c|c|c|}
\hline & Without teeth & With teeth \\
\hline Reference frequency & $345.5 \mathrm{kHz}$ & $248.0 \mathrm{kHz}$ \\
\hline Frequency at maximum speed & $345.5 \mathrm{kHz}$ & $248.5 \mathrm{kHz}$ \\
\hline
\end{tabular}

In the next stage, by exchanging the spring with higher stiffness to make pushing force increase, the goal output torque will be obtained.

\section{Conclusions}

The authors have concluded as follows.

1) The authors have made a new design of stator and rotor of micro ultrasonic motor and manufacture it to elucidate the characteristics of it.

2) The authors have demonstrated that the stator with teeth has better characteristics of rotational speed and resonant frequency.

3) The first trial motor showed the possibility of the goal of $5 \mu \mathrm{Nm}$ and $3 \mathrm{rpm}$ with a reduction gear system successfully.

\section{Acknowledgement}

This work was supported by Acquisition, Technology and Logistics Agency of Japan. 


\section{References}

[1] Chen S., Mulgrew B., Grant P. M. A clustering technique for digital communications channel equalization using radial basis function networks. IEEE Transactions on Neural Networks, Vol. 4, Issue 4, 1993, p. 570-590.

[2] Sashida T., Kenjo T. An Introduction to Ultrasonic Motors. Oxford University Press, Oxford, 1993.

[3] Ferreira A., Minottia P. High-performance load-adaptive speed control for ultrasonic motors. Control Engineering Practice, Vol. 6, Issue 1, 1998, p. 1-13.

[4] Hoshina M., Mashimo T., Fukaya N., Matsubara O., Toyama S. Spherical ultrasonic motor drive system for pipe inspection. Advanced Robotics, Vol. 27, Issue 3, 2013, p. 199-209.

[5] Takesue N., Ohara T., Ishibashi R., Toyama S., Hoshina M., Hirai Y., Fukaya N., Arata J., Fujimoto H. Position control methods of spherical ultrasonic motor. Proceedings of IEEE/RSJ International Conference on Intelligent Robots and Systems, 2010, p. 3061-3066.

[6] Moriya T., Furukawa Y., Akano Y., Nakajima A. Experimental Study on a Miniature Ultrasonic Motor Using a Coiled Stator. IECEI Technical Report, No. US2005-29, 2005, p. 41-45, (in Japanese). 